\title{
Brain lateralization involved in visual recognition of conspecifics in coral reef fish at recruitment
}

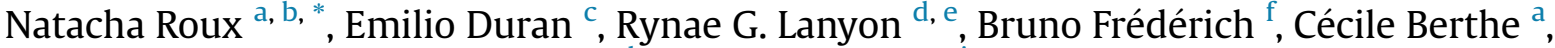 \\ Marc Besson ${ }^{a}$, g, Danielle L. Dixson ${ }^{\text {h}}$, David Lecchini ${ }^{a}$, ${ }^{3}$ \\ ${ }^{a}$ USR 3278, CNRS-EPHE-UPVD, CRIOBE, Moorea, French Polynesia \\ b UMR 7232, CNRS-UPMC, Observatoire Océanologique de Banyuls-sur-Mer, Banyuls-sur-Mer, France \\ ${ }^{\mathrm{c}}$ Laboratorio de Psicobiologia, University of Sevilla, Campus Santiago Ramon y Cajal, Sevilla, Spain \\ d School of Marine Studies, Institute of Marine Resources, University of the South Pacific, Suva, Fiji \\ e Institute for Pacific Coral Reefs, IRCP, Moorea, French Polynesia \\ ${ }^{\mathrm{f}}$ Laboratoire de Morphologie Fonctionnelle et Evolutive, AFFISH Research Center, Institut de Chimie B6c, Université de Liège, Liège, Belgium \\ ${ }^{\mathrm{g}}$ Molecular Zoology Team, Institut de Génomique Fonctionnelle de Lyon, Université Lyon 1, CNRS UMR 5242, Ecole Normale Supérieure de Lyon, Lyon, \\ France

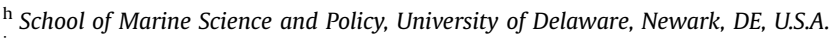 \\ ' Laboratoire d'Excellence 'CORAIL', Paris Sciences Lettres (PSL), Moorea, French Polynesia
}

\section{A R T I C L E I N F O}

\section{Article history:}

Received 12 December 2015

Initial acceptance 27 January 2016

Final acceptance 29 March 2016

MS number 15-01049R

\section{Keywords:}

brain lateralization

coral reef fishes

recruitment

telencephalon

visual recognition
In vertebrates, brain functional asymmetries are widespread and increase brain performance. Some species of fishes are known to have brain asymmetries; however, little information is available on brain lateralization in coral reef fishes and the impact this could have during the recruitment phase. In this study, soldierfish, Myripristis pralinia, at the larval and juvenile stage recognized conspecifics through visual cues. Larvae with the ablation of either the right or left telencephalic hemisphere lost the attraction towards conspecific cues. In contrast, juveniles with the ablation of the right (but not left) telencephalic hemisphere still displayed a preference towards conspecific visual cues. These results suggest the left telencephalic hemisphere is responsible for the lateralization process used in the visual recognition of coral reef fish juveniles. The determinism of lateralized perception of conspecifics during fish ontogeny may be a consequence of genetic factors, linked with the metamorphosis processes and/or environmental factors such as predation at recruitment.

(c) 2016 The Association for the Study of Animal Behaviour. Published by Elsevier Ltd. All rights reserved.
Lateralization, the preference for one side of the body over the other, is a common phenomenon in vertebrate (for a review see Salva, Regolin, Mascalzoni, \& Vallortigara, 2012) and invertebrate species (for a review see Frasnelli, Vallortigara, \& Rogers, 2012). Brain lateralization is thought to increase cognitive abilities, behavioural complexity or behavioural laterality, leading to advantages in brain function (Vallortigara \& Rogers, 2005). Several studies have explored the role lateralization plays in emotion or cognitive decisions. For cognition, the brain's right hemisphere is responsible for processing novel items and/or items requiring a rapid response. The brain's left hemisphere is used to categorize stimuli and/or process information requiring consideration of alternatives (Rogers, Vallortigara, \& Andrew, 2013). It has been

\footnotetext{
* Correspondence: N. Roux, UMR 7232, CNRS-UPMC, Observatoire Océanologique de Banyuls-sur-Mer, 1 avenue du Fontaulé, 66650 Banyuls-sur-Mer, France.

E-mail address: natacha.roux@obs-banyuls.fr (N. Roux).
}

suggested that the brain's ability to process positive and negative emotions utilizes the right hemisphere for both positive and negative emotional responses. Alternatively, the valence theory proposes that the right hemisphere is dominant for negative emotions and the left hemisphere is primarily used with positive emotions (e.g. Hook-Costigan \& Rogers, 1998; Quaranta, Siniscalchi, \& Vallortigara, 2007; Siniscalchi, Lusito, Vallortigara, \& Quaranta, 2013). Empirical evidence supports the cognition and emotion theories; however, it can be argued that additional species from a more diverse group must be studied to come to any general conclusion (e.g. Jozet-Alves et al., 2012; McManus, 2005).

Most species of fishes in coral reefs have a stage-structured life history. A relatively sedentary benthic stage (juveniles and adults) produces a highly dispersive pelagic larval stage (Leis, Siebeck, \& Dixson, 2011). At the end of the larval phase, organisms are required to enter the benthic reef environment, termed recruitment (Lecchini \& Galzin, 2003). During this time period, species-specific 
changes in morphology and physiology, referred to as metamorphosis, occur (Leis \& McCormick, 2002). Larvae lose many of the characteristics that enhanced survival in the pelagic environment, such as transparency (McCormick, 1999). In turn, once settlement occurs newly settled recruits rapidly develop features better suited for the reef habitat, such as pigmentation (Dufour, Lecaillon, \& Romans, 2000). Moreover, during the recruitment phase, fish larvae are subjected to strong selective pressures to choose a suitable reef habitat that will facilitate survival and growth. Studies have documented up to $90 \%$ larval mortality in the first 7 days on the reef (Doherty et al., 2004; Lecchini, Osenberg, Shima, St Mary, \& Galzin, 2007). Recruitment of new individuals is a critical process in the maintenance and recovery of marine communities (Lecchini \& Galzin, 2003). Correct habitat identification depends strongly on the ability of marine larvae to recognize and respond to sensory signals from conspecifics, habitat components and predators (Barth et al., 2015). Many coral reef fish species recognize their conspecifics using visual cues (Huijbers et al., 2012; Lecchini, Peyrusse, Lanyon, \& Lecellier, 2014; O'Connor et al., 2015). Despite the importance of visual, acoustic and chemical cues during the recruitment process (Leis et al., 2011), very little information is available on the relationship between brain morphology or lateralization and the behavioural and social interactions of coral reef fishes (Barth et al., 2015). A link between brain area and life history traits has been found. Indeed, nocturnally active fish species that spend less than 30 days in the pelagic environment before settling have a larger optic tectum and telencephalon than diurnal fish species that spend less than 15 days in the ocean (Lecchini, Lecellier et al., 2014). Additionally, behavioural lateralization in coral reef fish larvae is impaired by ocean acidification (Domenici et al., 2014, 2012; Nilsson et al., 2012). Few studies have explored whether lateralization could vary across the development of an individual (Concha, Bianco, \& Wilson, 2012; Rogers et al., 2013; Skiba, Diekamp, \& Güntürkün, 2002). Zebrafish, Danio rerio, 6-21 days posthatching show a significant left-eye preference when examining their reflection in a mirror (Sovrano \& Andrew, 2006). Cuttlefish, Sepia officinalis, 3-45 days posthatching progressively develop a left turning bias (Jozet-Alves et al., 2012). Both studies indicate the development of the lateralization process during an early life history stage. Coral reef fish offer an important group of organisms to study the development of lateralization. Selection favours individuals on reefs that chose an ideal location, and the visual recognition of conspecifics provides an indication of optimal settlement sites. The use of visual cues could be favoured by the lateralization process in cognition, with larvae recognizing familiar conspecifics compared to unfamiliar heterospecifics.

Overall, understanding the ontogeny of lateralization is essential for complete comprehension of the larval recruitment processes. This is especially important as changing climate conditions impact lateralization's function (Nilsson et al., 2012). Here, we tested coral reef fish at the larval (premetamorphosis) and juvenile (metamorphosed) stage to better understand the role that lateralization plays in the cognitive recognition of visual conspecific cues. The importance of telencephalic hemispheres in the visual recognition of conspecifics was tested using behavioural assays conducted on fish with and without one or other hemisphere of the telencephalon. This determined whether the lateralization of the brain is present at the larval and/or juvenile stages during recruitment.

\section{METHODS}

\section{Specimen Collection}

Fish larvae were collected nightly from February to June 2011 and September 2014 using crest nets set on the west coast of
Moorea Island, French Polynesia $\left(17^{\circ} 31^{\prime} 03,56^{\prime \prime} \mathrm{S}, 146^{\circ} 55^{\prime} 21,53^{\prime \prime} \mathrm{W}\right)$. This sampling technique collects fish larvae in the process of recruitment (Lecchini, Dufour, Stand, \& Galzin, 2004; Lecchini et al., 2006; Lo-Yat et al., 2011). A rectangular mouth (1 m wide, $2 \mathrm{~m}$ high) net $(1 \mathrm{~mm}$ mesh) was oriented perpendicular to the water flow, designed to retain all incoming larvae (for methods see Lecchini et al., 2004). Larvae were collected between 1700 and 0600 hours, to maximize the capture of nocturnal recruiting larvae while minimizing the amount of debris collected during daylight hours (Lecchini et al., 2006). Crest nets do not target specific species.

The soldierfish, Myripristis pralinia, was chosen due to the high number of individuals collected (total: 148 larvae) and the biology of the species. Myripristis pralinia live in shoals that include all sessile ontogenetic stages: newly settled recruits, juveniles and adults (Lecchini \& Galzin, 2005). Fish larvae and juveniles use vision to recognize conspecifics during recruitment (Barth et al., 2015; Lecchini, Shima, Banaigs, \& Galzin, 2005). To determine the difference in lateralization between life history stages, both larvae (size: $5.8 \pm 0.2 \mathrm{~cm}$ ) and juveniles (size: $6.2 \pm 0.1 \mathrm{~cm}$ ) were tested. Juveniles were obtained by rearing collected larvae in aquaria for 7 days, which ensured that metamorphosis was finished.

\section{Brain Surgery}

To determine the importance of brain lateralization in conspecific recognition, surgery was necessary. Surgical procedures followed modified methods from Salas, Broglio, Duran, Gomez, and Rodriguez (2008) and Durán, Ocaña, Broglio, Rodríguez, and Salas (2010). Surgery on larvae was conducted within $24 \mathrm{~h}$ of collection. Surgery on juveniles was conducted 7 days after larval collection. An individual was first anaesthetized in $0.07 \mathrm{~g} /$ litre of MS222 (m-aminobenzoic acid ethyl ester, methanosulphate salt) dissolved in sea water. Once unconscious, the fish was placed in a surgical chamber. Two PVC side plates kept the fish stable during surgery. The fish was maintained alive and unconscious using a tube inserted into the mouth continuously flushing sea water containing MS222 ( $0.07 \mathrm{~g} /$ litre). The telencephalic hemispheres were exposed through four incisions on the top of the skull using conventional dissection equipment. The removed piece of the cranium was placed on wet cotton until the end of the surgery. The left or right telencephalic hemisphere was removed using a micropipette connected to a syringe. Regular verifications were made through a binocular microscope to avoid surgical mistakes. After hemisphere removal, the piece of cranium was replaced in its original position and fixed with cyanoacrylate glue. To ensure that the surgical procedure did not affect fish behaviour, the surgery was conducted on 10 individuals of each stage and the skull was closed without ablation, termed a sham operation. After surgery, the fish was woken by circulating untreated sea water through the tube inserted into the mouth. All surgeries were conducted in less than $10 \mathrm{~min}$. Overall, four experimental groups of fishes were considered: nonoperated (NS), sham-operated (Sh), right telencephalic hemisphere removed (RT) and left telencephalic hemisphere removed (LT).

\section{Visual Recognition of Conspecifics by Fish Larvae and Juveniles}

The fish were behaviourally assessed using a threecompartment test chamber $(60 \times 12 \mathrm{~cm}$ and $10 \mathrm{~cm}$ high (Lecchini, Peyrusse, et al., 2014; Fig. 1). The side compartments consisted of two transparent Plexiglas panels separated by $1 \mathrm{~cm}$ placed to create barriers at $8 \mathrm{~cm}$ from each end, resulting in a central compartment (length: $32 \mathrm{~cm}$ ). The central compartment was separated into three 


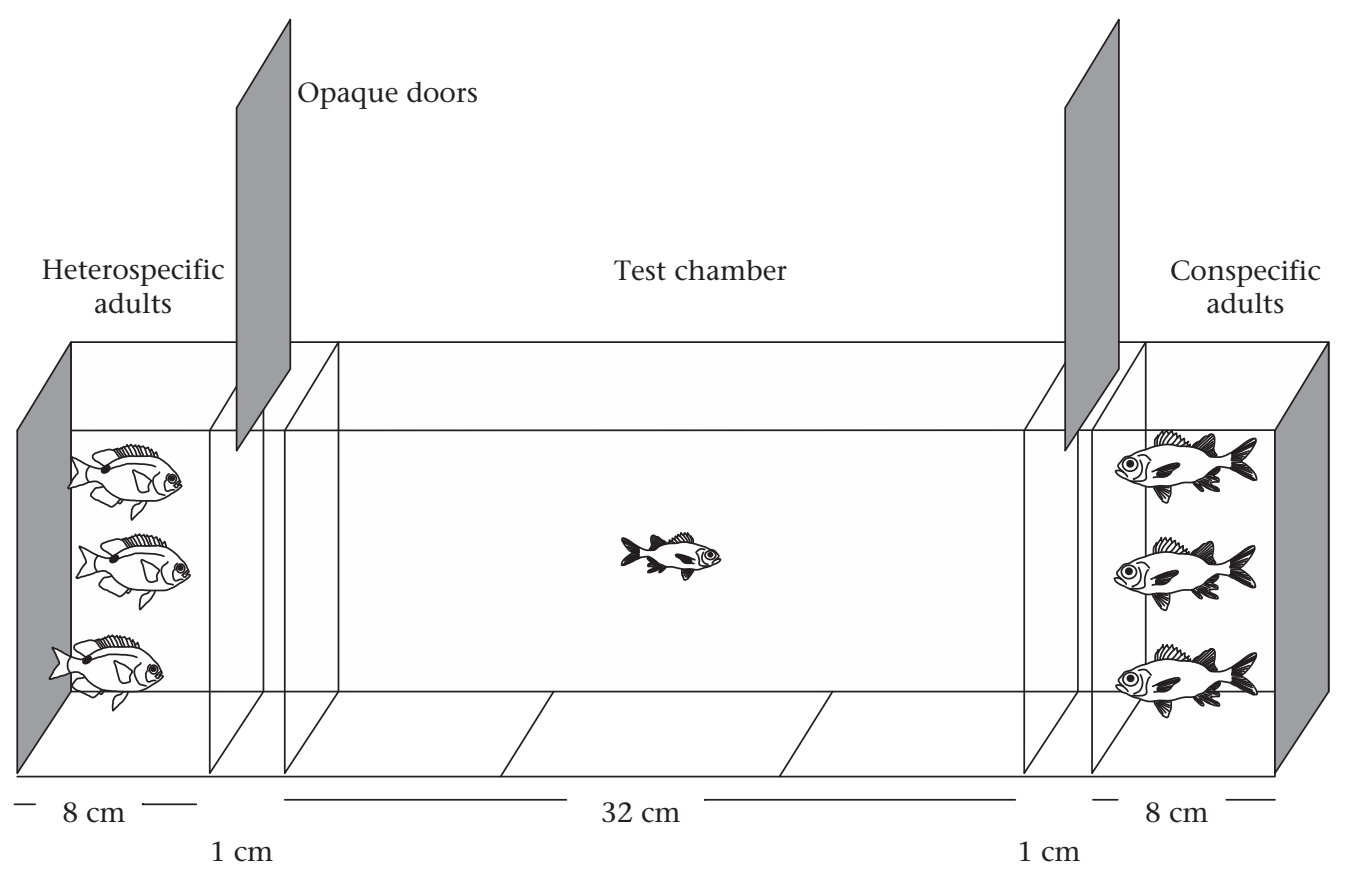

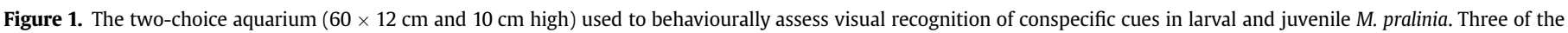
chamber sides were opaque to limit distractions to the test fish.

equal parts (length: $10.6 \mathrm{~cm}$ ) using two lines drawn on the bottom of the aquaria to identify the three equal compartments.

This experimental system isolated the larva or juvenile, placed into the central compartment, from chemical and acoustic cues emitted by the conspecifics and heterospecifics used as visual cue transmitters (Lecchini, Lecellier et al., 2014; Lecchini, Osenberg et al., 2007). A hydrophone placed in the centre of the aquarium (HTI-96MIN with inbuilt preamplifier; sensitivity $165 \mathrm{~dB}$ re $1 \mathrm{~V} / \mu \mathrm{Pa}$; frequency range $2 \mathrm{~Hz}-30 \mathrm{kHz}$; High Tech Inc., Gulfport, MS, U.S.A.) connected to a solid-state recorder (Edirol R-09HR 16-bit recorder; sampling rate $44.1 \mathrm{kHz}$; Roland Systems Group, Bellingham, WA, U.S.A.) verified auditory stimuli were not being transmitted from visual cue sources. Conspecifics and heterospecifics were, respectively, M. pralinia (range size: $7.1 \pm 0.3 \mathrm{~cm}$ ) and Stegastes nigricans (range size: $6.9 \pm 0.2 \mathrm{~cm}$ ) adults captured in the Moorea lagoon (see Appendix). Adults used for visual cue transmission, regardless of species, did not display any type of aggressive behaviour (quick movements, charging towards the test fish, etc.). Instead, adults remained fairly stationary in the chambers, allowing larvae and juveniles to freely move within the test chamber uninhibited by potential aggressive interactions. The lack of aggressive displays by adults towards test subjects was further verified by the movement patterns of the fish. Larvae and juveniles were not seen to approach either the heterospecific or conspecific side and quickly retreat. Preliminary field observations in Moorea showed no competition for space or food between S. nigricans and M. pralinia (Lecchini \& Galzin, 2005; Lecchini, Nakamura, Tsuchiya, \& Galzin, 2007).

For each fish group (NS, Sh, RT and LT), the following protocol was applied: one individual (71 larvae or 66 juveniles) was introduced into the middle of the central compartment for a 1 min habituation period. Prior to the fish being introduced into the test aquaria, opaque screens were placed between the Plexiglas barriers in order to avoid visual contact between the tested individual and fish placed in adjacent compartments. Following the 1 min habituation period, the opaque screens were removed. The location of fish in each of the three parts of the aquarium was recorded every second for $1 \mathrm{~min}$. After each trial, the aquarium was emptied and washed with freshwater. To exclude a possible side bias, compartments containing conspecifics and heterospecifics were randomized (see also methods in Lecchini, Peyrusse et al., 2014; O'Connor et al., 2015).

Two separate one-way analyses of variance (ANOVA) with the fixed factor of surgical treatment were run on each ontogenetic stage (larval and juvenile) to determine whether the mean percentage time spent near the conspecific differed between brain ablation treatments. A post hoc Tukey test was conducted to compare the results from individuals receiving no operation to other experimental time (i.e. Sh, RT, LT). A significant difference indicated that the individual spent either significantly more time or significantly less time near conspecifics. Last, a two-way ANOVA was conducted to compare the results between the larval and juvenile stages.

Preliminary blank experiments were conducted to ensure no potential side biases existed. Blank experiments recorded the position of an individual $M$. pralinia, as described above, but with empty adjacent compartments. Another set of preliminary experiments was conducted to determine the use of visual cues in the recognition of both conspecifics and heterospecifics. The position of an individual $M$. pralinia placed in the centre of the central compartment was recorded using methods described above. One adjacent compartment contained heterospecific $S$. nigricans adults and the other remained empty (see Appendix).

\section{Ethical Note}

To minimize adverse impacts on the welfare of fish during this experiment, $M$. pralinia larvae or juveniles were anaesthetized using MS222. Surgery began only once the fish was fully unconscious. The ethical guidelines of French Polynesia and the surgery protocol of Salas et al. (2008) and Durán et al. (2010) were followed. All fish tested were kept in aquaria for 15 days after the experiment to ensure survival. Of the 148 fish used in this study only $5 \%$ died (3\% larvae and $2 \%$ juveniles). Data of deceased fish were removed from the analysis. After 15 days, fish were euthanized using a long exposure in MS222. 


\section{RESULTS}

\section{Visual Recognition of Conspecifics by Fish Larvae}

Surgical treatments significantly impacted conspecific recognition in $M$. pralinia larvae (ANOVA: $F_{3,67}=4.49, P=0.003$ ). Both control treatments, $M$. pralinia larvae without surgery (NS) and those whose skull was opened (Sh), significantly preferred conspecific visual cues to heterospecific visual cues (Tukey test: NS: $P=0.02$; Sh: $P=0.002$ ). The larvae without surgery spent $56 \%$ of their trial time in the compartment closest to the conspecifics. Individuals that had their skull opened but no ablation spent $69 \%$ of their time near the conspecifics (Fig. 2a). In contrast, larvae with right or left telencephalon ablation (RT and LT) did not show an attraction to conspecifics (RT: $P=0.80$; LT: $P=0.73$ ), spending $33 \%$ and $34 \%$ of their time near the conspecific cue, respectively (Fig. 2a).

\section{Visual Recognition of Conspecifics by Fish Juveniles}

As seen with the larval M. pralinia, a significant difference was found between surgical treatments in juveniles (ANOVA: $F_{3,62}=3.76, P=0.009$ ). Juveniles without surgery (NS), individuals whose skull was opened (Sh) and those whose right telencephalon was removed (RT) spent significantly more time in the section nearest conspecifics (NS: $P=0.006$; Sh: $P=0.04$; RT: $P=0.03$ ). In contrast, juveniles whose left telencephalon was removed (LT) displayed no significant preferences for conspecifics, spending $42 \%$ of their time in the compartment closest to the heterospecifics and $25 \%$ of their time in the compartment closest to the conspecifics $(P=0.84$; Fig. 2b).

No significant difference was found in the amount of time spent near conspecifics when comparing the two ontogenetic stages of the control experiment: both larvae and juveniles preferred to spend time near the conspecific cue (two-way ANOVA: $P=0.81$ ). However, when the larval and juvenile results from the right ablated telencephalon treatment were compared, the larval stage spent significantly less time near the conspecific than the juvenile stage (two-way ANOVA: $P=0.009$ ).

\section{DISCUSSION}

At both larval and juvenile stages, $M$. pralinia was able to recognize their conspecifics through visual cues. Juveniles with right telencephalon ablations (but not left) were still able to recognize the conspecifics. However, larvae with either right or left telencephalon ablations lost the attraction to conspecific visual cues (Fig. 2). Therefore, our results indicate that juvenile $M$. pralinia are lateralized, preferentially using the left telencephalic hemisphere to recognize conspecifics. Both larvae and juveniles showed no interaction (neither repulsion nor attraction) towards the
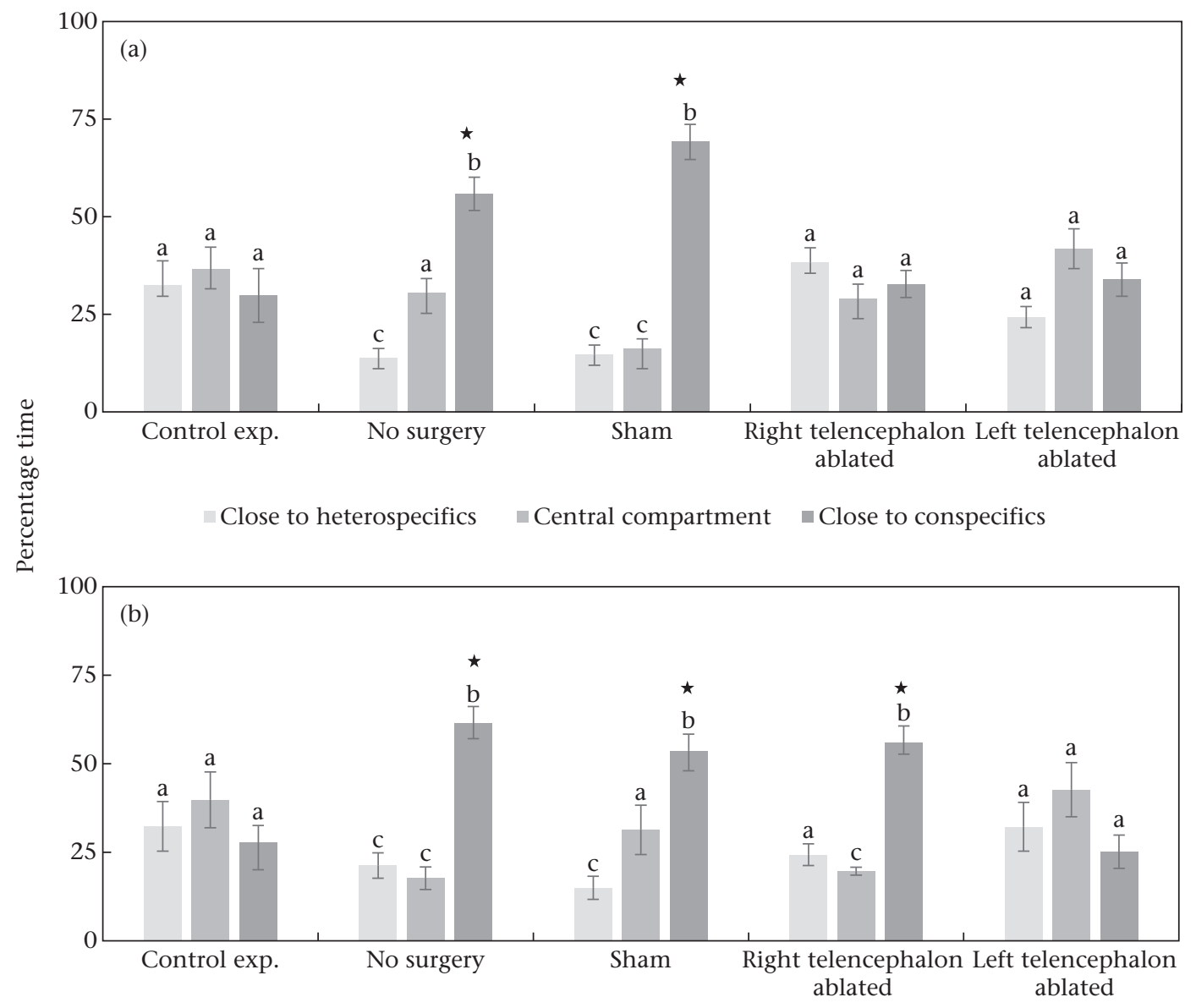

Close to heterospecifics $\backsim$ Central compartment $\backsim$ Close to conspecifics

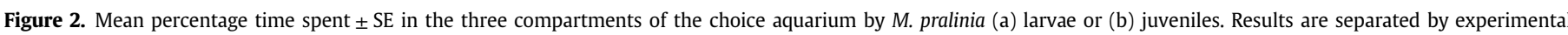

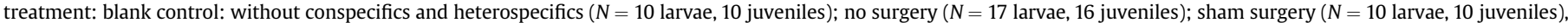

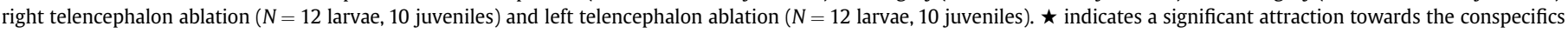
(ANOVA: $P<0.05$ ). Letters $(\mathrm{a}, \mathrm{b}, \mathrm{c})$ above the bars indicate significant groupings by a post hoc Tukey test. 
heterospecific cue, suggesting that S. nigricans was considered unfamiliar by $M$. pralinia larvae and juveniles.

Lateralization in response to social stimuli is often dominated by the right telencephalon hemisphere in response to visual cues provided by conspecifics (humans: Sergent, Signoret, Bruce, \& Rolls, 1992; monkeys: Hook-Costigan \& Rogers, 1998; birds: Vallortigara, Rogers, Bisazza, Lippolis, \& Robins, 1998; freshwater fishes: Sovrano, Bisazza, \& Vallortigara, 2001). Our results suggest that M. pralinia juveniles use the left hemisphere of the brain to recognize their conspecifics and support existing evidence that some vertebrate taxa (mainly freshwater fish and birds) may be able to differentiate, using either the left or right hemisphere, between familiar and unfamiliar conspecifics (Concha et al., 2012; Kaarthigeyan \& Dharmaretnam, 2005; Sovrano, 2004), Chicks, Gallus gallus domesticus, for example, use the right hemisphere for the recognition of familiar objects or conspecifics and the left hemisphere for objects that are unfamiliar (Vallortigara \& Andrew, 1991, 1994). The fish Xenopoecilus sarasinorum show preferential use of the monocular field from the left eye when presented with familiar conspecifics and a slight preferential use of the right eye with unfamiliar conspecifics (Sovrano, 2004). Myripristis pralinia larvae were captured before recruiting into a reef. As a result, the larvae and juveniles were naïve, having had no previous experience with adult fishes. Juveniles used in this study were held individually for 7 days prior to experimental testing, without any contact with other fishes including conspecifics of the same cohort. Myripristis pralinia larvae, juveniles and adults have different colour patterns at Moorea island (Maamaatuaiahutapu, Remoissenet, \& Galzin, 2006). The conspecific presented in the chamber (adults) would be considered unfamiliar for both larvae and juveniles individually tested, justifying the need to use the left hemisphere (Culum Brown, Western, \& Braithwaite, 2007; Concha et al., 2012). Further experiments should be conducted on juveniles that have been allowed contact with older conspecifics compared to those held in solitary confinement. This would determine whether M. pralinia are able to distinguish between familiar and unfamiliar conspecifics, and which telencephalon part is used for this differentiation.

The use of sensory cues during the recruitment process is widely accepted in larval ecology (Kingsford et al., 2002; Leis et al., 2011). Many studies have found that recruiting larvae utilize the cues emitted by conspecifics for habitat recognition (Booth, 1992; Huijbers et al., 2012; Lecchini et al., 2005). Visual and chemical cues appear to be especially important during recruitment (Devine, Munday, \& Jones, 2012; Dixson et al., 2008; Dixson, Munday, Pratchett, \& Jones, 2011; Lecchini, Nakamura et al., 2007; Lecchini, Osenberg et al., 2007). The indifference shown by M. pralinia towards the visual cues of heterospecifics and preference towards the visual cues of conspecifics strongly suggests the importance of conspecific recognition. However, it is plausible that the fish tested here were responding to information other than conspecific identification, such as body shape or colour. Adult M. pralinia have a characteristic red body whereas the heterospecific, S. nigricans are predominantly black; therefore larvae and juveniles may have displayed a colour preference rather than conspecific preference. Given the known importance of conspecific recognition, this seems unlikely, but further experiments are required to disprove the idea. However, the significant difference found between experimental treatments in our study indicates the importance of the left hemisphere when juveniles process visual information. This finding is independent of the specific preference used by test subjects for position within the test chamber.

Overall, our results suggest that coral reef fish juveniles potentially use the left telencephalic hemisphere in the lateralization process of visual cue recognition. The extrapolation of results to other species should be done with caution, as this study was conducted on a single species. The determinism of lateralized perception of conspecifics during fish ontogeny was not tested in our study. Determinism may be a consequence of genetic factors controlling the metamorphosis process and/or environmental factors such as predation at recruitment. In the freshwater fish Brachyraphis episcopi, individuals collected in areas of high and low predation pressure differ in both the strength and direction of the lateralized responses (Brown, Gardner, \& Braithwaite, 2004). Settling coral reef fish recruits are subjected to strong predation pressure. Up to $90 \%$ of newly settled fish are removed by predation during the first week postrecruitment (Doherty et al., 2004; Lecchini, Nakamura et al., 2007; Lecchini, Osenberg et al., 2007). Moreover, during the recruitment phase, reef fish juveniles are subjected to additional intra- and interspecific interactions compared to fish larvae in open ocean ecosystems (Barth et al., 2015; Lecchini \& Galzin, 2003; Leis et al., 2011). Thus, the brain lateralization of coral reef fish occurring at metamorphosis, from an oceanic larva to a reef juvenile, could increase their chance of survival and favour intraspecific interactions. A similar hypothesis was suggested in cuttlefish: JozetAlves et al. (2012) suggested that the development of lateralized response could allow juvenile cuttlefish to assess visual information faster and thus better deal with predation pressure. Additional experiments are necessary to determine whether brain lateralization established during ontogeny is a consequence of a genetic factor linked with the metamorphosis process and/or environmental factors such as predation. The diversity found on coral reefs and differences seen here with other vertebrate groups indicate that this ecosystem should be an area of future research on the evolution of brain lateralization.

\section{Acknowledgments}

This work was supported by a Tahiti Pearls grant IRCP-2011-4 to R.G.L. (IRCP-Tahiti Perles 2012). We thank F. Vincent and the staff of the CRIOBE research station for logistical support. The authors declare that no competing interests, including financial interests, exist. D.L. and E.D. conceived and designed the experiments, N.R., R.G.L., C.B., B.F. and M.B. performed the experiments and analysed the data and N.R., D.L.D. and D.L. wrote the paper.

\section{References}

Barth, P., Berenshtein, I., Besson, M., Roux, N., Parmentier, E., Banaigs, B., et al. (2015). From the ocean to a reef habitat: how do the larvae of coral reef fishes find their way home. Vie et milieu, 95(2), 91-100.

Booth, D. (1992). Larval settlement patterns and preferences by domino damselfish, Dascyllus albisella. Journal of Experimental Marine Biology Ecology, 155, 85-104.

Brown, C. Gardner, C. \& Braithwaite, V. A. (2004). Population variation in lateralized eye use in the poeciliid Brachyraphis episcopi. Proceedings of the Royal Society of London B: Biological Sciences, 271(Suppl_6), S455-S457. http:// dx.doi.org/10.1098/rsbl.2004.0222.

Brown, C., Western, J., \& Braithwaite, V. A. (2007). The influence of early experience on, and inheritance of, cerebral lateralization. Animal Behaviour, 74(2), 231-238. http://dx.doi.org/10.1016/j.anbehav.2006.08.014.

Concha, M. L., Bianco, I. H., \& Wilson, S. W. (2012). Encoding asymmetry within neural circuits. Nature Reviews Neuroscience, 13(12), 832-843. http://dx.doi.org/ 10.1038/nrn3371.

Devine, B., Munday, P., \& Jones, G. (2012). Rising $\mathrm{CO}_{2}$ concentrations affect settlement behaviour of larval damselfishes. Coral Reefs, 31, 229-238.

Dixson, D. L., Jones, G. P., Munday, P. L., Planes, S., Pratchett, M. S., Srinivasan, M., et al. (2008). Coral reef fish smell leaves to find island homes. Proceedings of the Royal Society B: Biological Sciences, 275(1653), 2831-2839. http://dx.doi.org/ 10.1098/rspb.2008.0876.

Dixson, D. L., Munday, P. L., Pratchett, M., \& Jones, G. P. (2011). Ontogenetic changes in responses to settlement cues by Anemonefish. Coral Reefs, 30(4), 903-910. http://dx.doi.org/10.1007/s00338-011-0776-9.

Doherty, P. J., Dufour, V., Galzin, R., Hixon, M. A., Meekan, M. G., \& Planes, S. (2004). High mortality during settlement is a population bottleneck for a tropical surgeonfish. Ecology, 85, 2422-2428.

Domenici, P., Allan, B., McCormick, M. I., \& Munday, P. L. (2012). Elevated carbon dioxide affects behavioural lateralization in a coral reef fish. Biol Lett, 8(1), 78-81. http://dx.doi.org/10.1098/rsbl.2011.0591. 
Domenici, P., Allan, B. J. M., Watson, S.-A., McCormick, M. I., \& Munday, P. L. (2014). Shifting from Right to Left: The Combined Effect of Elevated CO2 and Temperature on Behavioural Lateralization in a Coral Reef Fish. PLoS ONE, 9(1), e87969. http://dx.doi.org/10.1371/journal.pone.0087969.

Dufour, V., Lecaillon, G., \& Romans, P. (2000). La colonisation des récifs coralliens par les larves de poissons. Oceanis, 26, 523-541.

Durán, E., Ocaña, F. M., Broglio, C., Rodríguez, F., \& Salas, C. (2010). Lateral but not medial telencephalic pallium ablation impairs the use of goldfish spatial allocentric strategies in a 'hole-board' task. Behavioural Brain Research, 214(2), 480-487. http://dx.doi.org/10.1016/j.bbr.2010.06.010.

Frasnelli, E., Vallortigara, G., \& Rogers, L. J. (2012). Left-right asymmetries of behaviour and nervous system in invertebrates. Neuroscience and Biobehavioral Reviews, 36(4), 1273-1291. http://dx.doi.org/10.1016/j.neubiorev.2012.02.006.

Hook-Costigan, M. A., \& Rogers, L. J. (1998). Eye preferences in common Marmosets (Callithrix jacchus): influence of age, stimulus, and hand preference. Laterality: Asymmetries of Body, Brain and Cognition, 3(2), 109-130. http://dx.doi.org/ $10.1080 / 713754297$.

Huijbers, C. M., Nagelkerken, I., Lössbroek, P. A., Schulten, I. E., Siegenthaler, A., Holderied, M. W., et al. (2012). A test of the senses: fish select novel habitats by responding to multiple cues. Ecology, 93(1), 46-55.

Jozet-Alves, C., Viblanc, V. A., Romagny, S., Dacher, M., Healy, S. D., \& Dickel, L. (2012). Visual lateralization is task and age dependent in cuttlefish, Sepia officinalis. Animal Behaviour, 83(6), 1313-1318. http://dx.doi.org/10.1016/j.anbehav.2012.02.023.

Kaarthigeyan, J., \& Dharmaretnam, M. (2005). Relative levels of motivation and asymmetries of viewing and detour task in guppies (Poecilia reticulata). Behavioural Brain Research, 159(1), 37-41. http://dx.doi.org/10.1016/j.bbr.2004.09.024.

Kingsford, M., Leis, J. M., Shanks, A., Lindeman, K. C., Morgan, S. G., \& Pineda, J. (2002). Sensory environments, larval abilities and local self-recruitment. Bulletin of Marine Science, 70, 309-340.

Lecchini, D., Dufour, V., Stand, S., \& Galzin, R. (2004). Study of the fish larval flux at Moorea Island: is the spatial scale significant? Journal of Fish Biology, 65, 1142-1146.

Lecchini, D., \& Galzin, R. (2003). Synthèse sur l'influence des processus pélagiques et benthiques, biotiques et abiotiques, stochastiques et déterministes, sur la dynamique de l'autorecrutement des poissons coralliens. Cybium, 27(3), 167-184.

Lecchini, D., \& Galzin, R. (2005). Spatial repartition and ontogenetic shifts in habitat use by coral reef fishes (Moorea, French Polynesia). Marine Biology, 147(1), 47-58. http://dx.doi.org/10.1007/s00227-004-1543-z.

Lecchini, D., Lecellier, G., Lanyon, R. G., Holles, S., Poucet, B., \& Duran, E. (2014). Variation in brain organization of coral reef fish larvae according to life history traits. Brain Behavior and Evolution, 83(1), 17-30. http://dx.doi.org/10.1159/ 000356787.

Lecchini, D., Nakamura, Y., Tsuchiya, M., \& Galzin, R. (2007). Spatiotemporal distribution of nocturnal coral reef fish juveniles in Moorea Island, French Polynesia. Ichthyological Research, 54(1), 18-23. http://dx.doi.org/10.1007/s10228-006-0368-9.

Lecchini, D., Osenberg, C. W., Shima, J. S., St Mary, C. M., \& Galzin, R. (2007) Ontogenetic changes in habitat selection during settlement in a coral reef fish: ecological determinants and sensory mechanisms. Coral Reefs, 26(2), 423-432. http://dx.doi.org/10.1007/s00338-007-0212-3.

Lecchini, D., Peyrusse, K., Lanyon, R. G., \& Lecellier, G. (2014). Importance of visual cues of conspecifics and predators during the habitat selection of coral reef fish larvae. Comptes Rendus Biologies, 337(5), 345-351. http://dx.doi.org/10.1016/ j.crvi.2014.03.007.

Lecchini, D., Polti, S., Nakamura, Y., Mosconi, P., Makoto, T., Remoissenet, G., etal. (2006). New perspectives on aquarium fish trade. Fisheries Science, 72(1), 40-47.

Lecchini, D., Shima, J., Banaigs, B., \& Galzin, R. (2005). Larval sensory abilities and mechanisms of habitat selection of a coral reef fish during settlement. Oecologia, 143(2), 326-334. http://dx.doi.org/10.1007/s00442-004-1805-y.

Leis, J. M., \& McCormick, M. I. (2002). The biology, behavior, and ecology of the pelagic, larval stage of coral reef fishes. In P. F. Sale (Ed.), coral reef fishes: Dynamics and diversity in a complex ecosystem (pp. 171-199). London, U.K.: Academic Press.

Leis, J. M., Siebeck, U., \& Dixson, D. L. (2011). How nemo finds home: the neuroecology of dispersal and of population connectivity in larvae of marine fishes. Integrative and Comparative Biology, 51(5), 826-843. http://dx.doi.org/10.1093/ icb/icr004.

Lo-Yat, A., Simpson, S. D., Meekan, M., Lecchini, D., Martinez, E., \& Galzin, R. (2011). Extreme climatic events reduce ocean productivity and larval supply in a tropical reef ecosystem. Global Change Biology, 17, 1695-1702.

Maamaatuaiahutapu, M., Remoissenet, G., \& Galzin, R. (2006). Guide d'identification des larves de poissons récifaux de Polynésie française. Taravao, French Polynesia: Téthys Editions.

McCormick, J. M. (1999). Delay metamorphosis in Acanthurus triostegus. Marine Ecology Progress Series, 176, 25-38.

McManus, I. C. (2005). Unity in the wild variety of nature, or just variety? Behavioral and Brain Sciences, 28(4), 606-608.

Nilsson, G. E., Dixson, D. L., Domenici, P., McCormick, M. I., Sørensen, C., Watson, S.A., et al. (2012). Near-future carbon dioxide levels alter fish behaviour by interfering with neurotransmitter function. Nature Climate Change, 2(3), 201-204. http://dx.doi.org/10.1038/nclimate1352.

O'Connor, J. J., Lecchini, D., Beck, H., Cadiou, G., Lecellier, G., Booth, D., et al. (2015) Sediment pollution impacts sensory ability and performance of settling coralreef fish. Oecologia, 1-11. http://dx.doi.org/10.1007/s00442-015-3367-6.

Quaranta, A., Siniscalchi, M., \& Vallortigara, G. (2007). Asymmetric tail-wagging responses by dogs to different emotive stimuli. Current Biology, 17(6), R199-R201. http://dx.doi.org/10.1016/j.cub.2007.02.008.
Rogers, L. J., Vallortigara, G., \& Andrew, R. J. (2013). Divided brains: The biology and behavior of brain asymmetries. Cambridge, U.K.: Cambridge University Press.

Salas, C., Broglio, C., Duran, E., Gomez, A., \& Rodriguez, F. (2008). Spatial learning in fish. In R. Menzel (Ed.), Learning theory and behavior (pp. 499-528). Oxford U.K.: Elsevier:

Salva, O., Regolin, L., Mascalzoni, E., \& Vallortigara, G. (2012). Cerebral and behavioural asymmetries in animal social recognition. Comparative Cognition \& Behavior Reviews, 7, 110-138. http://dx.doi.org/10.3819/ccbr.2012.70006.

Sergent, J., Signoret, J.-L., Bruce, V., \& Rolls, E. T. (1992). Functional and anatomical decomposition of face processing: evidence from prosopagnosia and PET study of normal subjects [and discussion]. Philosophical Transactions of the Royal Society London B: Biological Sciences, 335(1273), 55-62. http://dx.doi.org/10.1098/ rstb.1992.0007.

Siniscalchi, M., Lusito, R., Vallortigara, G., \& Quaranta, A. (2013). Seeing left- or rightasymmetric tail wagging produces different emotional responses in dogs. Current Biology, 23(22), 2279-2282. http://dx.doi.org/10.1016/j.cub.2013.09.027.

Skiba, M., Diekamp, B., \& Güntürkün, O. (2002). Embryonic light stimulation induces different asymmetries in visuoperceptual and visuomotor pathways of pigeons. Behavioural Brain Research, 134(1), 149-156.

Sovrano, V. A. (2004). Visual lateralization in response to familiar and unfamiliar stimuli in fish. Behavioural Brain Research, 152(2), 385-391. http://dx.doi.org/ 10.1016/j.bbr.2003.10.022.

Sovrano, V., \& Andrew, R. (2006). Eye use during viewing a reflection: behavioural lateralisation in zebrafish larvae. Behavioural Brain Research, 167(2), 226-231. http://dx.doi.org/10.1016/j.bbr.2005.09.021.

Sovrano, V. A., Bisazza, A., \& Vallortigara, G. (2001). Lateralization of response to social stimuli in fishes: a comparison between different methods and species. Physiology and Behaviour, 74(1), 237-244.

Vallortigara, G., \& Andrew, R. J. (1991). Lateralization of response by chicks to change in a model partner. Animal Behaviour, 41, 187-194.

Vallortigara, G., \& Andrew, R. J. (1994). Differential involvement of right and left hemisphere in individual recognition in the domestic chick. Behavioural Processes, 33(1), 41-57.

Vallortigara, G., \& Rogers, L. J. (2005). Survival with an asymmetrical brain: advantages and disadvantages of cerebral lateralization. Behavioral and Brain Sciences, 28(4), 575-588.

Vallortigara, G., Rogers, L., Bisazza, A., Lippolis, G., \& Robins, A. (1998). A complementary right and left hemifield used during predatory and agonistic behaviours in toads. NeuroReport, (9), 3341-3344.

\section{APPENDIX. CONTROL TREATMENT OF AQUARIA BIAS AND HETEROSPECIFIC TREATMENT TO CHOOSE THE SPECIES}

A control treatment was conducted to test potential bias of the apparatus. Here, one M. pralinia individual was introduced into the centre of the central compartment, and no fishes were introduced into the two adjacent compartments. A chi-square test was carried out to check that the control distribution was not significantly different to the theoretical distribution (i.e. fish spending 33\% of their time in each part of the aquarium). The results showed no significant differences between the control distribution and the theoretical ones for both larvae and juveniles $(P>0.05)$. Considering our control distributions homogeneous, they were used to compare the experimental distributions.

To determine that both larvae and/or juveniles were able to distinguish and display a preference towards the visual cues of conspecifics, heterospecifics were used as cue transmitters. However, heterospecifics should not attract/repel both $M$. pralinia larvae and juveniles. To control for this, one individual was introduced into the centre of the central compartment and heterospecifics (in our study S. nigricans) were placed into one of the two adjacent compartments, the other one remaining empty. A chi-square test was carried out to confirm the distribution was not significantly different to the control distribution. The results showed no significant differences to the control distribution $(P>0.05)$ proving that both larvae and juveniles are indifferent to $S$. nigricans, confirming our choice. Moreover, visual observations of the aquaria showed no competition between M. pralinia at larval or juvenile stages and S. nigricans. Thus we can be sure that it is recognition that occurs rather than avoidance of a particular trait of heterospecifics such as larger size or vigorous locomotion. Last, some field surveys at Moorea showed, first, the presence of $M$. pralinia schools in which larvae, juveniles and adults live together, and, second, no competition for space or food between S. nigricans and M. pralinia (Lecchini, Nakamura, et al., 2007). 